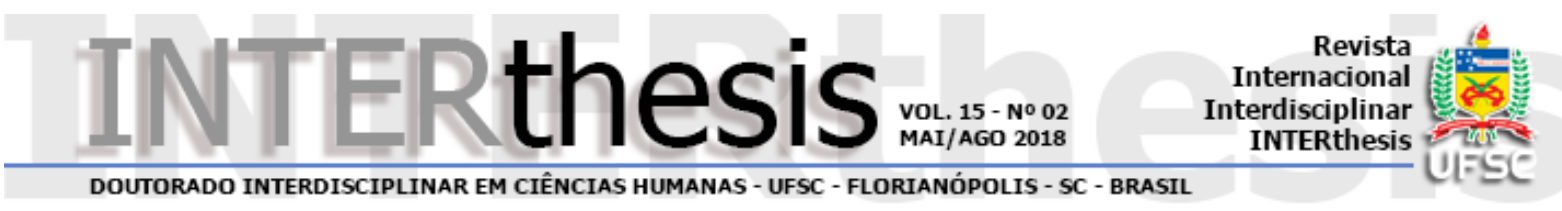

\title{
CANTOS FEMININOS: A PARTICIPAÇÃO DA MULHER NA RENOVAÇÃO DAS TRADIÇÕES LUSO-BRASILEIRAS
}

\section{Resumo:}

Ricardo Mendes Mattos ${ }^{1}$

O presente artigo discute a participação dos cantos de mulheres na renovação das tradições luso-brasileiras. Para tanto, coteja versos tradicionais de coletivos femininos - nomeadamente Catadoras de Mangaba, Meninas de Sinhá e cantigas registradas pela Cia. Cabelo de Maria - com algumas versões de cancioneiros populares portugueses. A grande quantidade de versos idênticos ou similares deixa claro o papel fundamental dos cantos femininos na renovação de tradições portuguesas no Brasil, além de apresentar elementos do modo de vida, da expressão cultural e das formas de luta da mulher nas comunidades tradicionais do mundo contemporâneo.

Palavras-chave: Cultura Popular. Cantos de Mulheres. Literatura Oral. Tradição Luso-Brasileira.

\section{INTRODUÇÃO}

"As mulheres não são somente o principal arquivo das tradições orais; são também as autoras de muitas destas tradições"- afirma Silvio Romero (1888, p. 233), pioneiro nas coletas da literatura tradicional nacional. Mais atualmente, em seu registro da poesia oral no Conselho de Baião (Portugal), Carlos Nogueira pondera: “...na nossa experiência de recolha, as mulheres são na generalidade informantes mais valiosas, quantitativa e qualitativamente" (2011c, p. 38-9).

O reconhecimento da importância das mulheres na produção e transmissão da literatura oral remete a própria aurora dos estudos sobre tais tradições. O clássico poeta português Almeida Garret, desbravador dos estudos da literatura oral lusitana, destaca lembranças de sua infância que o levaram ao acervo da cultura tradicional: "Foi o caso, que umas criadas velhas de minha mãe, e uma mulata brasileira de minha irmã, apareceram sabendo vários romances..." (GARRET, apud BRAGA, 1883, p. XIII). Nessa última passagem, não apenas fica clara a relevância das mulheres, mas

1 Doutor em Psicologia Social da Arte pela Universidade de São Paulo, São Paulo, SP, Brasil. E-mail: ricardomendesmattos@gmail.com 
o entrosamento entre as culturas brasileira e portuguesa na formação de uma tradição oral em comum.

Na cultura portuguesa, tal fenômeno acompanha a própria criação da cantoria popular. Em Cantares do Povo Português, Rodney Gallop (1960, p. 24-25) ressalta que as mulheres são portadoras de uma tradição muito antiga, que se manifesta com pungência desde o século XII até a atualidade. De fato, a afirmação pode ser verificada, nos diais de hoje, nas contemporâneas desgarradas e outras cantigas ao desafio que trazem o duelo poético entre um homem e uma mulher. Tais desafios são importantes porque neles a mulher não apenas canta, mas, de certa forma, discute a própria estrutura patriarcal da sociedade contemporânea.

Por sua vez, Rodrigues Lapa (1977, p. 113) aponta que a saliência das mulheres na cantoria tradicional está ancorada em sua importância social e econômica. Isso, por que em seu entendimento, o papel das mulheres nas canções de amor e amigo, destaca que a ausência dos homens - recrutados para a guerra ou imigrados-favorece o empenho das mulheres no cultivo das terras.

Ou seja, a contribuição das mulheres nos cantos tradicionais brota de sua centralidade no interior das comunidades rurais. A esse respeito, é Carlos Nogueira quem estuda a questão mais a fundo. Para o autor, as mulheres, nas comunidades rurais portuguesas, têm aumentado muito sua participação no trabalho rural - num processo denominado "feminização da agricultura". Dessa forma, o papel central da mulher na vida familiar se fortalece por sua participação econômica e cultural: "A mulher, contudo, não se afirma na comunidade apenas pelo trabalho. Impõe-se também pelo uso da palavra literária, pelo canto, exercendo o papel de transmissora dos conhecimentos que garantem a coesão da comunidade" (NOGUEIRA, 2011c, p. 39-41).

Ao estudar a presença das quadras tradicionais no contexto urbano contemporâneo da cidade do Porto (Portugal), Francisco Topa (1998) verificou que são sobretudo as jovens as responsáveis pela renovação da tradição.

Temos ressaltado a participação da mulher portuguesa na produção e transmissão de tradições orais por considerar a importância do legado lusitano na constituição da poesia oral cantada no Brasil - como bem notaram diversos estudiosos do assunto, de Celso Magalhães a Câmara Cascudo (1984). Contudo, se observarmos as tradições de matriz africana, também é avultante a importância comunitária e cultural da mulher. 
Restringindo-se ao legado lusitano, a presente pesquisa pretende demonstrar a participação das mulheres na produção, transmissão e renovação de cantos tradicionais portugueses no Brasil, na criação de uma tradição luso-brasileira. Para tanto, estudamos a poesia presente em gravações atuais feitas por coletivos de mulheres que adotam a questão do gênero como definidor de sua identidade grupal: Catadoras de Mangaba (no álbum Quero ver rodar, 2015), Cia. Cabelo de Maria (no álbum Cantos de Trabalho, 2007) e Meninas de Sinhá (no álbum Tá caindo fulô, 2006). Tais gravações foram comparadas com algumas versões dos conhecidos cancioneiros populares portugueses, coletados desde o século XIX, em diversas regiões de Portugal.

Considerando a grande quantidade de versos semelhantes, cantados por mulheres portuguesas e brasileiras, a pesquisa assumiu um caráter eminentemente exploratório, restringindo-se a apresentar os versos coincidentes e deixando para futuros estudos uma análise mais detalhada de tais cantos.

Far-se-á a exposição dos dados a partir dos trabalhos dos coletivos femininos brasileiros (Cia. Cabelo de Maria, Catadoras de Mangaba e Meninas de Sinhá), comparando seus versos com aqueles dos cancioneiros portugueses. Ao final, realizar-se-á uma breve síntese sobre a participação das mulheres no fortalecimento da tradição luso-brasileira da cantoria popular.

\section{CIA. CABELO DE MARIA}

A pesquisadora de cantos de trabalho de mulheres, Renata Mattar, gravou parte de sua coleta no CD Cantos de Trabalho, da Cia. Cabelo de Maria. A estudiosa acompanhou durante anos algumas comunidades, e afirma: "Muitas das cantigas de trabalho que encontramos nas casas de farinha, na destalação do fumo, com as fiandeiras de algodão, são cantigas de roda de versos com a estrutura e melodias muito portuguesas" (O Canto das Mulheres, 2008).

Alguns cantos de trabalho das ladeiras de fumo de Arapiraca (Alagoas) são bons exemplos dessa influência portuguesa. Há um verso muito tradicional encontrado em diversos cancioneiros portugueses e cantado, ainda hoje, em inúmeras comunidades:

Com pena pego na pena,

Com pena quero escrever;

Caiu-me a pena no chão

Com pena de te não ver (BRAGA, 1867, p. 129). 
Além do Arquipélago dos Açores $^{2}$, onde Teófilo Braga recolheu esta quadra, ela também foi coligida em Ribatejo (REDOL, 1950, p. 147) e em Baião (Nogueira, 2011 b, p. 232). Um tema parecido surge nos cantos das desta ladeiras de fumo de Arapiraca:

Com pena peguei na pena

Com pena fui escrever

A pena caiu da mão

No tijolo fez um "e" (Cia. Cabelo de Maria, 2007).

Trata-se de uma variação da quadra tradicional, também similar às versões portuguesas como:

Atirei a pena ao ar,

Caiu no chão, fez um S;

Ande lá por onde andar,

Nunca o meu amor se esquece. (BRAGA, 1867, p. 129; OLIVEIRA, 1905, p. 226; REDOL, 1950, p. 114).

Como notaram diversos estudiosos do cancioneiro popular tradicional, é muito comum uma mesma quadra possuir diversas versões a depender do local e da época em que é cantada. Isso ocorre, certamente, porque as formas de transmissão da tradição oral contam com uma reinvenção constante do verso, muito distinto da fixação inalterável da palavra escrita. Há outros versos improvisados em Arapiraca que realizam similar renovação da tradição:

\author{
Lá vem a lua saindo \\ Meu benzinho venha ver \\ Você sai pra ver a lua \\ Eu saio pra ver você (Cia. Cabelo de Maria, 2007).
}

Há diversas estrofes portuguesas que se aproximam dos versos das destaladeiras:

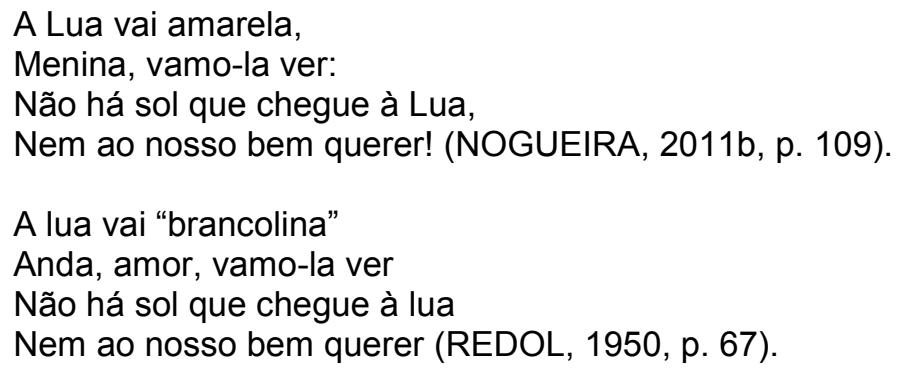

A Lua vai amarela, Menina, vamo-la ver: Não há sol que chegue à Lua, Nem ao nosso bem querer! (NOGUEIRA, 2011b, p. 109).

A lua vai "brancolina"

Anda, amor, vamo-la ver

Não há sol que chegue à lua

Nem ao nosso bem querer (REDOL, 1950, p. 67).

Há outras estrofes, contudo, que permanecem praticamente idênticas às suas matrizes portuguesas:

Quem me dera, dera, dera uma chuva bem fininha pra molhar a sua cama e você dormir na minha (Cia. Cabelo de Maria, 2007).

${ }^{2} \mathrm{O}$ autor não especifica em quais das ilhas do referido arquipélago realizou a coleta da quadra citada. 


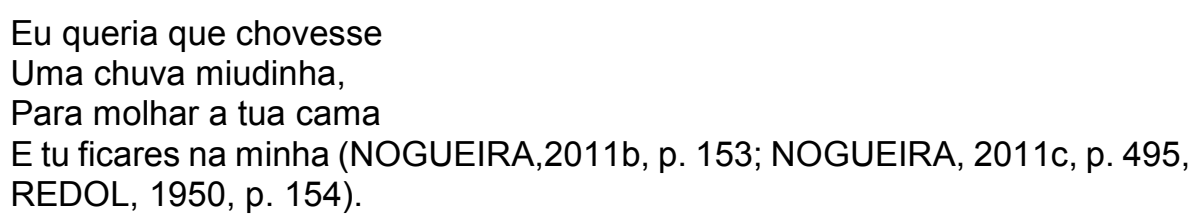

Veremos mais adiante como o verso "Quem me dera, dera, dera" é muito comum tanto em Portugal como no Brasil.

Em outra cantiga de Arapiraca, temos a seguinte sequência de versos:

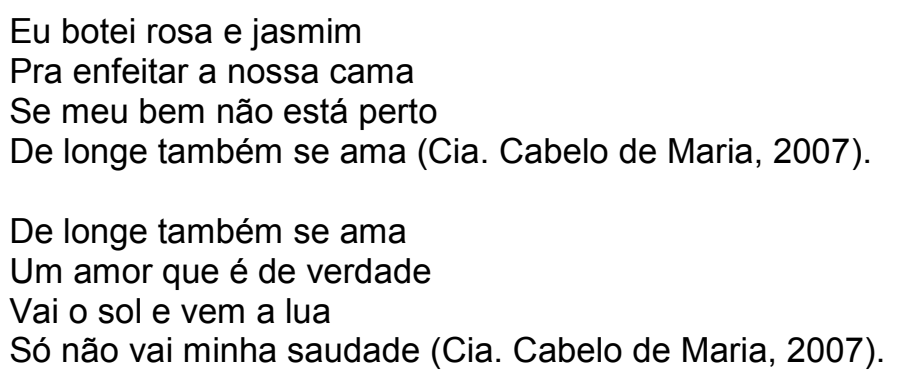

$\mathrm{O}$ ato de repetir, na segunda quadra, o último verso improvisado pela companheira que cantou a primeira estrofe, é uma regra de cantos improvisados, praticada na Europa desde os chamados trovadores medievais - conhecida como "leixapren". Nesse caso, é a segunda quadra quem guarda identidade com o cancioneiro português:

De longe também se ama,

Também se cria amizade;

De longe sente-se mais

O rigor duma saudade. (NOGUEIRA, 2011b, p. 272).

Além dos versos com uma identidade mais evidentemente observável, há também outros que lembram o cancioneiro português por uma metáfora usada ou pela composição poética empregada:

\author{
Se eu soubesse que tu vinhas \\ Fazia um dia maior \\ Dava um nó na fita verde \\ Prendia o raio do sol (Cia. Cabelo de Maria, 2007). \\ Sobrancelhas como as tuas \\ Impossível é havê-las: \\ São laços de fita preta. \\ Com que prendes as estrelas. (OLIVEIRA, 1905, p. 204).
}

Embora o tema seja distinto, o último dístico dos versos utiliza a imagem de uma "fita" presa a um "astro", de maneira muito parecida.

No verso seguinte, é o tema que possui semelhanças com seu congênere português:

Fui à fonte das pedrinhas

Fui fazer as minhas queixas 
Uma das pedras me disse:

"Amor firme não se deixa" (Cia. Cabelo de Maria, 2007).

Eu fui chorar saudades

Lá no canto do jardim

Uma flor me respondeu:

"Cala-te que tudo tem fim" (BRAGA, 1867, p. 288).

Por fim, um verso muitíssimo comum no Brasil, cantado pelas destaladeiras de fumo de Arapiraca, bem como pelas Meninas de Sinhá (2006), também ressoa uma estrofe portuguesa:

Da minha casa pra tua

Tem um riacho no meio

Tu de lá dá um suspiro

Eu de cá, suspiro e meio (Cia. Cabelo de Maria, 2007).

Tu de lá e eu de cá

Mete-se o rio ao meio.

Eu na fama já sou tua,

Hei-te amar a rio cheio! (NOGUEIRA, 2011b, p. 272).

O mesmo ocorre com um verso cantado em mutirão para bater o chão da casa de taipa, na mesma cidade de Arapiraca:

\author{
Eu vou embora, vou embora \\ Mas segunda-feira que vem \\ Mas quem não me conhece chora \\ Que dirá quem me quer bem (Cia. Cabelo de Maria, 2007). \\ Vou-m'embora, vou-m'embora, \\ Par'á semana que vem; \\ Quem me não conhece chora,' \\ Que fará quem me quer bem. (OLIVEIRA, 1905, p. 240).
}

Passemos a alguns versos cantados pelas "plantadeiras" de arroz de Propriá (Sergipe):

\author{
Cravo roxo na janela \\ É sinal de casamento \\ Menina recolhe o cravo \\ Pra casar ainda falta tempo (Cia. Cabelo de Maria, 2007).
}

É um verso idêntico àquele colhido por Teófilo Braga (1867, p. 131), Neves e Campos (1898, p. 90) e Alves Redol (1950, p. 73):

Cravo roxo á janela

É sinal de casamento;

Menina recolha o cravo,

Que o casar tem muito tempo.

As plantadeiras de arroz também cantam alguns versos cuja formulação poética lembra quadras tradicionais portuguesas, por exemplo:

Eu plantei e semeei

Rosa branca no terreiro 
Nunca vi mulher casada

Namorar rapaz solteiro (Cia. Cabelo de Maria, 2007).

Semeei, não apanhei,

Erva cidreira na areia;

Quem semeia, não apanha,

Que fará quem não semeia? (NOGUEIRA, 2011b, p. 64).

Há grande semelhança no primeiro dístico, muito embora tratem de temas distintos. A mesma similaridade é encontrada entre versos como os seguintes:

Atirei no sofrê

No pendão do milho

Atirei, mas não matei

No pendão do milho (Cia. Cabelo de Maria, 2007).

Atirei, não matei,

Se eu matara, melhor fora;

Atirei ao negro melro,

Acertei na triste rola (NOGUEIRA, 2011b, p. 83).

O primeiro verso coletado em uma cantiga do batalhão de trança da Fazenda Grota Funda (Serrinha - BA) é muito comum nos cancioneiros tradicionais de Portugal, encontrado em Braga (1867, p. 52; 1869, p. 48), Neves e Campos (1893, p. 219) e Nogueira (2011b, p. 184).

Por fim, ainda tendo como fonte as pesquisas da Cia. Cabelo de Maria, há uma quadra cantada na colheita de cacau de Salobrinho (Ilhéus, Bahia):

Cacaueiro abaixa o galho

Que eu quero me balançar

Meu benzinho aqui tão perto

E eu morrendo de chorar (Cia. Cabelo de Maria, 2007).

O primeiro dístico é muito comum no Brasil, mais frequentemente solicitando ao limoeiro que abaixe o galho:

Limoeiro baixa a galha

Que eu quero apanhar limão

Para limpar uma nódia

Eu tenho meu coração (Meninas de Sinhá, 2006).

Tais versos fazem referência a quadras tradicionais portuguesas, como a seguinte:

Limoeiro do Brasil

Bota p'ra cá um limão

Quero tirar uma nodoa

Que tenho no coração (NEVES e CAMPOS, 1898, p. 22).

É um exemplo da grande inventividade do poeta tradicional e da ininterrupta reinvenção da tradição. É possível que o verso coletado no século XIX, em Portugal, 
tenha dado ensejo a uma variação muita cantada no Brasil, a exemplo das Meninas de Sinhá.

\section{CATADORAS DE MANGABA}

Vamos agora ao registro Quero Ver Rodar, das Catadoras de Mangaba (2015), mulheres que trabalham na recolha do fruto da mangabeira, em Sergipe. É um coletivo de mulheres com atuação marcante na geração de renda, luta por direitos trabalhistas e preservação do meio ambiente. É interessante notar o subtítulo da gravação: "com as griôs da restinga sergipana". O termo griot foi cunhado pelos franceses como denominação para mestres tradicionais e "feiticeiros" africanos, especialmente aqueles relacionados à tradição oral - na África conhecidos como Djeli. Curiosamente, um termo francês, que se refere às personagens africanas, passa a denominar cantadoras brasileiras.

As catadoras cantam a seguinte estrofe, quase idêntica a sua correspondente portuguesa:

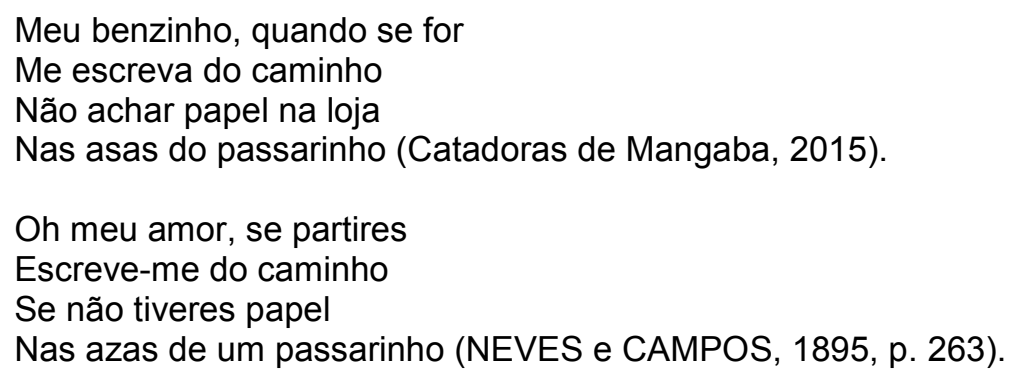

Outros versos das mulheres sergipanas que possuem muita equivalência com sua matriz lusitana são os seguintes:

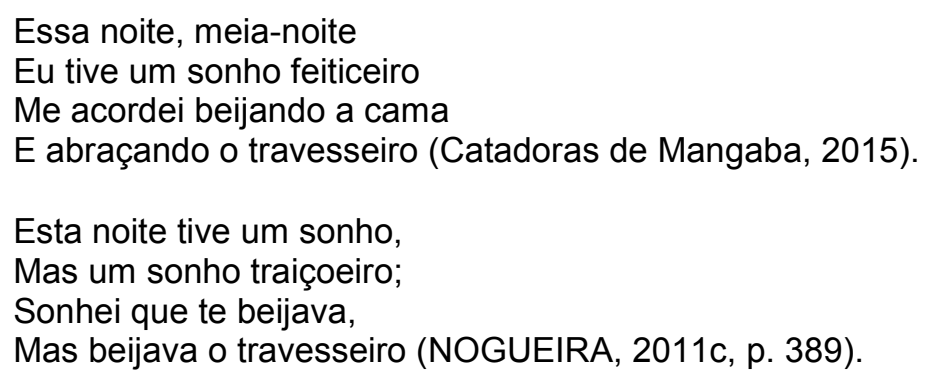

Em outras ocasiões, os versos brasileiros fazem referência explícita às estrofes portuguesas, mas com pequenas modificações, à moda da casa:

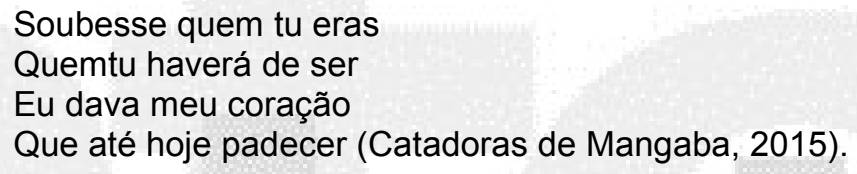


Se soubesse quem tu eras

Quem tu havias de ser

Não te davas falas minhas

Nem amor a conhecer (REDOL, 1950, p. 134)

Vejamos agora essa quadra:

Eu passei o rio a nado

No fundo de uma tigela

Arriscando a minha vida

Por uma moça donzela (Catadoras de Mangaba, 2015).

Observe-se que, embora seja cantado por mulheres, é um verso provavelmente masculino, a julgar pela proeza realizada para conquistar uma moça. O primeiro verso é muito corriqueiro nos cancioneiros populares portugueses. "Passei o mar a nado" é verso coletado por Braga (1867, p. 105), Nogueira (2011b, p. 117) e Redol (1950, p. 133). Vejamos um exemplo:

Eu passei o mar a nado

Nas ondas do teu cabelo

Agora posso dizer

Que passei o mar sem medo (THOMAZ, 1896, p. 46; NOGUEIRA, 2011b, p. 216).

Há também quadras cantadas pelas catadoras que remetem a mais de um verso português:

Açucena fez encontro No pé do manjericão

Quem se encosta nos meus braços

Está doente fica são (Catadoras de Mangaba, 2015).

Anda cá para os meus braços

Se vida tu queres ter

Os meus braços dão saúde

A quem está para morrer (REDOL, 1905, p. 118).

Salsa verde combatida

Ao pé do manjericão

Bem podemos ser amantes

Mas sempre dizer que não (NEVES e CAMPOS, 1898, p. 113).

Outras vezes, os versos não são tão parecidos na forma gramatical, mas sim no tema de que tratam:

Quem me dera eu vê hoje

Quem eu via nessa hora

Se eu não vesse a pessoa

O retrato me consola (Catadoras de Mangaba, 2015).

Quem me dera ver agora

Quem ontem à noite vi

Eu lhe dava o meu recado

Não lho mandava por ti (REDOL, 1950, p. 147). 
Já observamos como os versos com "quem me dera" são característicos tanto de cantos brasileiros como daqueles lusitanos:

Quem me dera, dera, dera

Quem me dera pra mim só

Me deitar na tua cama

Me cobrir com o teu lençol (Catadoras de Mangaba, 2015).

Quem me dera, dera, dera

Quem me dera, dera estar

Ao pé de ti, meu amor

Chegadinho a namorar (REDOL, 1950, p. 112).

O tema das reprimendas da mãe com relação aos comportamentos amorosos

dos filhos é muito comum no cancioneiro popular português. Nos versos das Catadoras de Mangaba o tema também aparece:

Minha mãe não quer que eu vá

Na casa do meu amor

Me amarra com a corrente

Se eu quebrar a corrente eu vou (Catadoras de Mangaba, 2015).

Minha mãe me ralhou

Por eu dar o meu ai-ai;

Ó minha mãe, não me ralhe,

Que você também o deu ao pai (NOGUEIRA, 2011c, p. 175).

Há outras consonâncias na relação entre as seguintes quadras:

Fui na fonte beber água

O capim cortou meu pé

Mas antes cortasse a língua

De quem fala de José (Catadoras de Mangaba, 2015).

Alecrim da Borda d'Água

Dá-lhe o vento torce o pé

Assim eu torcesse a língua

A quem diz o que não é (REDOL, 1950, p. 139).

Muita gente diz que ama

Mas não conhece o amor

Quem ama só foi querido

Quem sofre senti a dor (Catadoras de Mangaba, 2015).

Quem inventou a saudade

Não sabia o que era amor

Quem parte leva saudade

Quem fica chora de dor (BRAGA, 1867, p. 151).

Da Bahia me mandaram

Um presente, que tormenta

E mandaram pergunta

Se eu era ciumenta (Catadoras de Mangaba, 2015).

De Lisboa me mandaram

Um pratinho com o seu molho,

Com as asas de uma pulga

E o coração de um piolho (NOGUEIRA, 2011c, p. 167). 
Você diz que bala mata

$E$ bala não mata ninguém

A bala que me matou

Foi amar e querer bem (Catadoras de Mangaba, 2015).

Se os meus olhos fossem balas

Já te tinha trespassado

O teu peito, meu amor,

O meu amor adorado (OLIVEIRA, 1905, p. 221).

Nos quatro casos expostos, a quadra tradicional portuguesa oferece um modelo de composição que está presente nos cantos das mulheres brasileiras.

As catadoras cantam um verso popularíssimo no Brasil:

Menina dos olhos d'água

Me dê água pra eu beber

Não é sede, não é nada

É vontade de te ver (Catadoras de Mangaba, 2015).

Tal verso faz referência a uma quadra muito comum em Portugal, como, por exemplo, na seguinte variação:

Entre canas nascem silvas,

também rosas hão de haver;

Menina que estais na fonte,

Dae-me agua, quero beber (BRAGA, 1869, p. 132).

Maria Arminda Zaluar Nunes (1978), estudiosa do cancioneiro português, observa como o tema da água (fonte ou rio) é muito tradicional na poesia popular lusitana, desde a época trovadoresca. Porque os encontros entre jovens aconteciam nas fontes ou na beira dos rios, sendo o pedido de água uma paquera.

Por fim, há também um canto de despedida das catadoras que remete a fontes lusitanas:

\section{Adeus Corina}

Eu já vou me embora

Quem parte leva saudade

Quem fica também chora (Catadoras de Mangaba, 2015).

Não sei se te digo adeus

Se diga - fica-te embora

Um adeus é saudoso

Quem diz adeus sempre chora (BRAGA, 1869, p. 66)

Eu jurei de nunca mais

Dizer adeus a ninguém;

Quem parte leva saudades,

Quem fica saudades tem (NOGUEIRA, 2011b, p. 272-3). 


\section{MENINAS DE SINHÁ}

As Meninas de Sinhá formam um grupo de mulheres de comunidades de Belo Horizonte (Minas Gerais). Comecemos por uma série de quadras cantadas pelas meninas, praticamente idênticas às suas congêneres portuguesas:

Cravo branco na janela

É sinal de casamento

Tira o cravo e põe a rosa

Pra casar tem muito tempo (Meninas de Sinhá, 2006).

Cravo branco à janela

É sinal de casamento;

Menina, recolha o cravo

Que pra casar tem tempo (NOGUEIRA, 2011b, p. 90).

Oh, menina bonita

Como é que namora?

Põe o lencinho no bolso

Deixa a pontinha para fora (Meninas de Sinhá, 2006).

Menina, se quer saber

Como se agora namora,

Meta o lencinho ao bolso,

Deixe-lhe a ponta de fora (NOGUEIRA, 2011c, p. 287).

Por detrás daquela serra

Tem dois bancos de areia

Onde sentam as faladeiras

Pra falar da vida alheia (Meninas de Sinhá, 2006).

A cana verde no mar

Está escondida na areia;

É como as mocinhas novas

A falar da vida alheia (NOGUEIRA, 2011c, p. 244).

Fui ao mar apanhar laranja

Coisa quem no mar não tem

Lindinha toda molhada

Pela onda que vai e vem (Meninas de Sinhá, 2006).

Eu fui ó mar às laranjas,

Coisa que lá não havia;

Eu vim tão ademirada,

Das ondas qu'o mar fazia

(NOGUEIRA, 2011c, p. 504 - grifos do original).

Cada uma à sua maneira, tais quadras revelam comportamentos associados ao universo feminino luso-brasileiro: os códigos dos namoros, como o lenço para fora, ou os augúrios do casamento, como o cravo branco à janela; a paquera no mar, sob o pretexto de apanhar laranjas, ou o falar da vida alheia.

Há outros casos em que alguns versos da quadra são coincidentes:

Eu trepei no pé de lima

Chupei lima sem querer

Abracei com tanto espinho 
Pensando que era você (Meninas de Sinhá, 2006).

Anoiteceu-me num campo

Num sítio desconhecido

Abracei-me à própria terra

Cuidando que era contigo (CORTESÃO, 1914, p. 141).

Comparando essas quadras, observamos como os dois últimos versos tratam do mesmo tema, em formulação muito similar. O mesmo ocorre nas quadras seguintes, em que há coincidência no tema e identidade no primeiro verso:

As estrelas no céu correm

Eu também quero correr

Uma corre atrás da outra

Eu atrás do bem querer (Meninas de Sinhá, 2006).

As estrelas no céu correm

Todas n'uma carreirinha

Assim os amores correm

Da tua mão para a minha (NEVES e CAMPOS, 1893, p. 49).

Onde vai menina

Tão formosa assim?

- Eu vou colher as flores

Lá do seu jardim (Meninas de Sinhá, 2006).

Onde vais, Maria Alice,

Tão triste vais a chorar?

- Vou ter com o meu marido,

Está na taberna a jogar (NOGUEIRA, 2011c, p. 65).

Há outros casos em que as quadras são diferentes, porém adotam uma formulação gramatical semelhante:

Ajoelhado eu caí n'água

Ajoelhado fui ao fundo

Ajoelhado eu fui buscar

Meu amor no fim do mundo (Meninas de Sinhá, 2006).

Não boteis a prata à agua,

Que é pesada, vai ao fundo;

Não chores, amor, por mim,

Qu'eu ainda ando no mundo (NOGUEIRA, 2011b, p. 252).

Oh, que noite tão bonita

Oh, que céu tão estrelado

Quem me dera eu ver agora

O meu lindo namorado (Meninas de Sinhá, 2006).

Quem me dera ver agora

Quem a minha alma deseja.

Quem os meus braços apertam,

Quem a minha boca beija. (OLIVEIRA, 1905, p. 185).

Eu joguei uma lima d'agua

O limão saiu rodando

Quanto mais o limão roda

Mais amor eu vou tomando (Meninas de Sinhá, 2006). 
Deitei um limão correndo,

À tua porta bateu;

Quando o limão te quer bem,

Que fará quem o deitou! (NOGUEIRA, 2011b, p. 113).

Da Bahia me mandaram

Um presente original

Adivinha o que é

Uma mudinha de cacau (Meninas de Sinhá, 2006).

De Lisboa me mandaram

Um pratinho com o seu molho,

Com as asas de uma pulga

E o coração de um piolho (NOGUEIRA, 2011c, p. 167).

Uma cantiga obscena e bastante preconceituosa coletada por Carlos Nogueira, possui forma poética idêntica a uma quadra das Meninas de Sinhá:

Puta mãe e puta filha,

Puta era a tua tia;

Porque não hás-de ser puta,

Se és filha da putaria? (NOGUEIRA, 2011c, p. 228).

O meu pai se chama Caco

Minha mão Caca Maria

Caquiá com tanto caco

Eu sou filho da cacaria (Meninas de Sinhá, 2006).

Há também um verso inicial tradicional em Portugal e no Brasil, que é muito utilizado nas composições das cantadoras de Belo Horizonte:

Lá detrás daquela serra

Tem um poço de água fria

Onde meu bem lava o rosto

Fica claro como o dia (Meninas de Sinhá, 2006).

No alto daquela serra

'Stão fitinhas a voar;

O meu amor é caixeiro,

Tem bonitas pra me dar (NOGUEIRA, 2011c, p. 119).

As Meninas de Sinhá cantam outra estrofe clássica no Brasil que possui procedência portuguesa:

Se essa rua fosse minha

Eu mandava ladrilhar

Com pedrinhas de brilhante

Para o meu amor passar (Meninas de Sinhá, 2006).

Se esta rua fosse minha,

Mandava-a ladrilhar,

Com pedrinhas de brilhantes

Para o meu amor passar (NOGUEIRA, 2011b, p. 129-30).

Por fim, numa quadra de despedida, temos uma última reverberação de quadras lusitanas nas cantigas tradicionais do grupo Meninas de Sinhá: 
Amanhã eu vou me embora

Porque já falei que vou

Eu aqui não sou querido

Mas na minha terra eu sou (Meninas de Sinhá, 2006).

Adeus, que me vou embora

Adeus, que embora me vou

Daqui para a minha terra,

Que desta terra não sou (NOGUEIRA, 2011b, p. 53).

\section{CONCLUSÃO: A PARTICIPAÇÃO DAS MULHERES NA POESIA TRADICIONAL}

O presente artigo se limitou a enumerar alguns cantos de mulheres brasileiras que renovam uma tradição presente no cancioneiro popular português. O cotejamento dessas fontes permite afirmar que, de fato, no mundo contemporâneo, as mulheres possuem participação proeminente na renovação da poesia oral popular de tradição luso-brasileira. Tal afirmação abre possibilidades para futuras análises mais detalhadas que possam aprofundar a importância das mulheres nessa tradição, a exemplo das problematizações a seguir.

De maneira geral, predominam nas quadras os versos líricos com temas amorosos. Não se trata de uma característica específica dos cantos femininos, mas um aspecto ressaltado por muitos estudiosos do cancioneiro popular português. Palmeirim (1879), em sua obra A Poesia Popular nos Campos, detalhou diversas facetas desse lirismo lusitano presente nas trovas populares. Entre paqueras e desilusões, casamentos e mágoas, o autor destaca a participação das cantadoras na formulação das metáforas e temas tradicionais da poesia popular. Sendo o lirismo um traço central dessa tradição luso-brasileira, qual a contribuição das mulheres na fabulação dos temas amorosos?

O lirismo no ambiente rural, entre festas populares e figuras da natureza, traz muito do modo de vida e da sensibilidade dessas comunidades. Nos versos das mulheres brasileiras podemos observar também elementos da condição da mulher nesses locais. Ora até que ponto os cantos femininos podem ser considerados formas de expressão espontâneas da experiência das mulheres, em comunidades com traços patriarcais bem rigorosos?

Por fim, os coletivos de mulheres cantadoras também trazem pistas sobre a importância da mulher nas comunidades. Nos cantos de trabalho registrados pela Cia. Cabelo de Maria e na gravação das Catadoras de Mangaba, o trabalho coletivo e 
solidário se destaca como contexto de realização dos cantos. Mostra as feições das mulheres na comunidade, atrelando as atividades de produção da vida material com a própria atribuição de sentido à vida. É comum esse trabalho cantado se articular, ainda, com uma esfera de contestação política, dando ensejo a luta por direitos sociais e a discussão sobre a condição da mulher na contemporaneidade. Nos versos, nos cantos ou nos contextos de realização dessas tradições, também podemos inferir elementos da vida das mulheres nas comunidades tradicionais atuais.

Assim como os cantos retratados no presente artigo servem para se observar a condição da mulher em comunidades tradicionais, também possibilitam vislumbrar algumas de suas formas de expressão e luta no mundo contemporâneo. 


\title{
WOMEN'S SONGS: THE PARTICIPATION OF WOMEN IN THE RENEWAL OF PORTUGUESE-BRAZILIAN TRADITIONS
}

\begin{abstract}
:
This article discusses the participation of women's songs in the renewal of PortugueseBrazilian traditions. To do so, it contrasts traditional verses of Brazilian women's collectives - namely, Catadores de Mangaba, Meninas de Sinhá Girls and songs recorded by Cia. Cabelo de Maria - with some versions of popular Portuguese songbooks. The great number of identical or similar verses makes clear the fundamental role of women's songs in the renewal of Portuguese traditions in Brazil, as well as presenting elements of women's way of life, cultural expression and their struggles in the traditional communities of the contemporary world.
\end{abstract}

Keywords: Popular Culture. Songs of Women. Oral Literature. Portuguese-Brazilian Tradition.

\section{CANTOS FEMENINOS: LA PARTICIPACIÓN DE LA MUJER EN LA RENOVACIÓN DE LAS TRADICIONES LUSO-BRASILEÑAS}

\section{Resumen:}

El presente artículo discute la participación de los cantos de mujeres en la renovación de las tradiciones luso-brasileñas. Por lo tanto, coteja versos tradicionales de colectivos femeninos - como por ejemplo, Catadoras de Mangaba, Meninas de Sinhá e Cia. Cabelo de Maria - con algunas versiones de libros de canciones populares portuguesas. La gran cantidad de versos idénticos o similares deja claro el papel fundamental de los cantos de las mujeres en la renovación de las tradiciones portuguesas en Brasil, y presentar elementos de la forma de vida, expresión cultural y las formas de lucha de las mujeres en las comunidades tradicionales del mundo contemporáneo.

Palabras clave: Cultura Popular. Cantos de Mujeres. Literatura Oral. Tradición LusoBrasileña. 


\section{REFERÊNCIAS}

BRAGA, Theophilo. Cancioneiro Popular - coligido da tradição. Coimbra: Imprensa da Universidade, 1867.

BRAGA, Theophilo. Cantos Populares do Archipelago Açoriano. Porto: Typographia da Livraria Nacional, 1869.

BRAGA, Theophilo. Sobre a poesia popular do Brasil. Em: ROMERO, Silvio. Cantos Populares do Brasil (vol. I). Lisboa: Nova Livraria Internacional: 1883. pp. IX-XXXI.

CASCUDO, Luis da Câmara. Vaqueiros e cantadores. Belo Horizonte: Itatiaia; São Paulo: Editora da USP, 1984.

Catadoras de Mangaba. Quero ver rodar. Produção Musical e Direção Geral: Mary Barreto. Aracaju, 2015. 1 CD.

Cia. Cabelo de Maria. Cantos de trabalho. Sesc: 2007. 1 CD

CORTESÃO, Jaime. Cancioneiro Popular - antologia precedida dum estudo crítico. Porto: Renascença Portuguesa, 1914.

GALLOP, Rodney. Cantares do Povo Português. Lisboa: Instituto de Alta Cultura, 1960.

LAPA, Rodrigues. Lições de literatura portuguesa - época medieval. 9. ed.

Coimbra: Coimbra Editora, 1977.

Meninas de sinhá. Tá caindo fulô. Produção: Mais Brasil Música. Produção Musical: Gil Amâncio e Murillo Corrêa. Belo Horizonte, 2006. 1 CD.

NEVES, Cesar das; CAMPOS, Gualdino de. Cancioneiro de Músicas Populares (vol. I). Porto: TypographiaOccidental, 1893.

NEVES, Cesar das; CAMPOS, Gualdino de. Cancioneiro de Músicas Populares (vol. II). Porto: César, Campos e C., 1895. 
NEVES, Cesar das; CAMPOS, Gualdino de. Cancioneiro de Músicas Populares (vol. III). Porto: César, Campos e C., 1898.

NOGUEIRA, Carlos. A poesia oral em Baião - edição e estudo. 3. ed. Braga: Edições Vercial, 2011a.

NOGUEIRA, Carlos. Cancioneiro popular de Baião (vol. I). 2. ed. Braga: Edições Vercial, 2011b.

NOGUEIRA, Carlos. Cancioneiro popular de Baião (vol. II). 2. ed. Braga: Edições Vercial, 2011C.

NUNES, Maria Arminda Zaluar. O cancioneiro popular em Portugal. Instituto de Cultura Portuguesa / Secretaria de Estado da Cultura / Ministério da Educação e Cultura, 1978.

O CANTO DAS MULHERES - entrevista com Renata Mattar. Revista Raiz, 2008. Disponível em:

$<$ www.revistaraiz.uol.com.br/portal/index.php?option=com content\&taskview\&id=980 \&ltemid=169>. Acesso em: 12 mar.2016.

OLIVEIRA, Francisco Xavier d'Athaide. Romanceiro e cancioneiro do Algarve. Porto: Typographia Universal, 1905.

PALMEIRIM, L. A. A poesia popular nos campos - galeria de figuras portuguesas. Porto e Braga: Ernesto Chardron Editor, 1879.

REDOL, Alves. Cancioneiro do Ribatejo.[S.I]: Centro Bibliográfico, 1950.

ROMERO, Silvio. Estudos sobre a poesia popular do Brasil. Rio de Janeiro: Typ. Laummert\& C., 1888.

THOMAZ, Pedro Fernandes. Canções populares da Beira. Figueira: Imprensa Lusitana: 1896.

TOPA, Francisco. P'ra que nunca mais te esqueça - os versos dos álbuns infantojuvenis. Em: TOPA, Francisco. Olhares sobre a literatura infantil - Aquilino, Agustina, conto popular, adivinha e outras rimas. Porto: Edição do Autor, 1998. pp. 177-286. 